\section{Placement of a percutaneous endoscopic gastrostomy feeding tube via a cervical pharyngocutaneous fistula}

Percutaneous endoscopic gastrostomy (PEG) [1] is usually a straightforward procedure, but it can be difficult or even impossible to pass the gastroesophagoscope and the PEG feeding tube in some patients with head and neck cancers. Major head and neck surgery, radiotherapy, and tumor recurrance can all cause narrowing of the pharyngeal lumen, making oral feeding impossible. Meanwhile, cervical pharyngocutaneous fistulae are frequent sequelae in these patients [2]. Enteral nutrition of such patients is usually provided by means of a nasogastric tube, but this method has complications when used long term [3]. Nasogastric tubes can sustain the infection and the fistula in patients with this problem by causing chronic irritation.

Changing nasogastric tube feeding to PEG feeding for the provision of long-term nutritional support and to encourage closure of the fistula has a vital place in the management of these patients. However, the insertion of a gastroscope and a PEG tube via the oral route is often impossible because of the narrow pharyngeal space and the fistula. To overcome this problem, we performed complete gastroesophagoscopy and PEG tube insertion via a cervical fistula in three patients (Figure 1,2). A standard gastroesophagoscope was passed through the cervical fistula and a "pull back" type of PEG was performed in each case [1]. The procedure was performed under general anesthetic in one patient and using local anesthesia in two patients, and in all three cases the insertion of both the gastroscope and the PEG feeding tube was easy and successful. None of the patients experienced any discomfort and no immediate or long-term complications were noted. The author re-

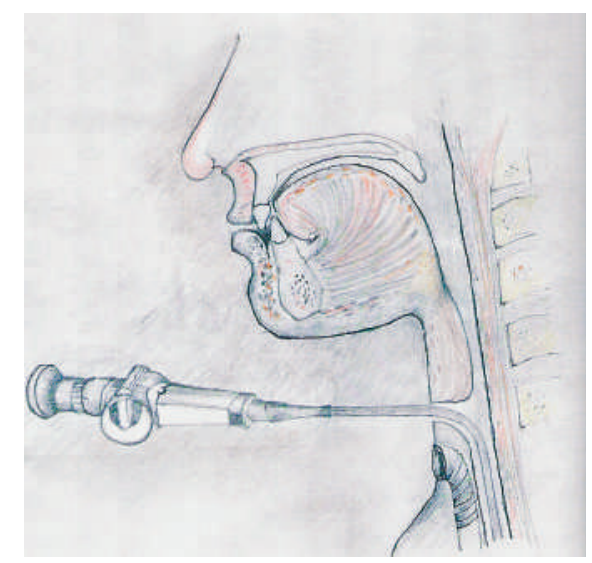

Figure 1 Introduction of the gastroesophagoscope via the patient's cervical fistula.

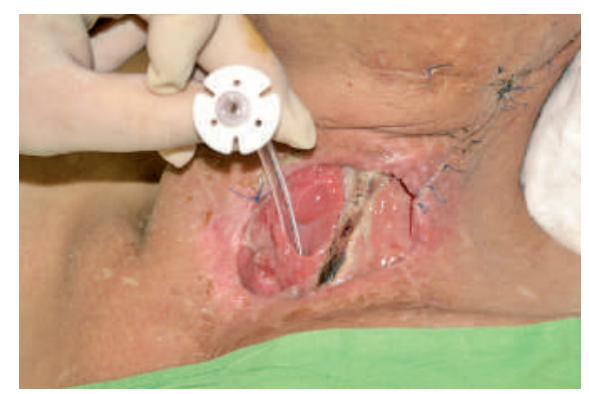

Figure 2 Pulling back the percutaneous endoscopic gastrostomy feeding tube through the cervical fistula.

commends performing PEG via a cervical fistula in patients with head and neck cancer when it is not possible to use the oral route because of narrowing of the pharyngeal lumen.

Endoscopy_UCTN_Code_TTT_1AO_2AK

\section{Lujber}

Department of Oto-Rhino-Laryngology, Head and Neck Surgery, Pécs University Medical School, Pécs, Hungary.

\section{References}

${ }^{1}$ Gauderer MW, Ponsky JL, Izant RJ. Gastrostomy without laparotomy: a percutaneous endoscopic technique. J Pediatr Surg 1980; 15: $872-875$

2 Stell PM, Cooney TC. Management of fistulae of the head and neck after radical surgery. J Laryngol Otol 1974; 88: 819-834

${ }^{3}$ Gibbons CL, Lavy CB, Bacon S. Complications of nasogastric feeding. BMJ (Clin Res Ed) 1988; 296: 1537

\section{Corresponding Author}

\section{Lubjer, M.D.}

Department of Oto-Rhino-Laryngology, Head and Neck Surgery

Pécs University Medical School

Munkácsy M. Str. 2

H-7621 Pécs

Hungary

Fax: $\quad+36-72228119$

E-mail: Lujber@yahoo.com 